\title{
o Legado Belinati
}

Luan Leite da Silva ${ }^{1}$

- Enviado em 13/05/2017

- Aprovado em 28/06/2017

\section{O Legado Belinati}

A família, a estrutura mais básica organizacional dada por relações de parentesco entre seus membros. Sob a égide dessa estrutura que a busca pelo poder se inicia e mantém-se ao longo dos anos, passando por processos de renovação e de assimilação de outros membros para que o poder concentre-se ante um seleto grupo formado, em sua maioria, por membros de determinadas famílias.

A partir de uma visão histórica, pode-se notar que as classes politicamente dominantes em uma determinada região são constituídas por uma finita gama de grupos familiares que. Estes grupos tendem a revezar-se no poder e, através de construções de laços matrimoniais, procuram-se unir e/ou absorver membros de outras famílias que também detêm algum tipo de poder local.

Pode-se pensar erroneamente que esse fenômeno para a manutenção do poder existente entre as classes dominantes ocorre apenas em regiões onde a configuração política local passou pelos processos de coronelismo e mandonismo. Ou seja, lugares onde séculos atrás famílias pioneiras exerciam seu comando através de relações de dependência com outras famílias, por concentrarem alguma forma de propriedade (no caso, a posse de latifúndios) para conseguirem efetuar a dominação. Porém, ao analisarmos uma cidade relativamente nova como Londrina, que possui apenas 81 anos, constatamos que não é necessário essa transição entre os sistemas políticos executados pelos coronéis locais para que uma classe dominante seja configurada e enraizada no berço da cidade (SILVA, 2015).

Tomando como base a família Belinati, hoje tradicional família da cidade, percebe-se que as relações existentes entre os detentores de poder vão além do capital financeiro que possuem, chegando às relações de parentesco e a apropriação de diversos cargos do setor público a fim de garantirem uma

\footnotetext{
${ }^{1}$ Discente do 8o período do curso de Engenharia Elétrica na Universidade Tecnológica Federal do Paraná - UTFPR. Endereço Eletrônico: luan@alunos.utfpr.edu.br
} 
proximidade com outros membros das classes dominantes possibilitando que relações possam ser falicitadas e pré-estipuladas.

\section{Histórico da família}

A partir da ideia de reocupação da região norte do estado promovida pela Companhia de Terras Norte do Paraná (CTNP), subsidiária da empresa inglesa Parana Plantantions Ltd. para a exploração de terras extremamente férteis, principalmente para o cultivo de café, promoveu-se um grande desenvolvimento urbano da região a partir do ano de 1924. A vinda dos produtores do setor cafeeiro para o norte fez com que um pequeno povoado se formasse no ano de 1929, denominado de Três Bocas ${ }^{2}$.

Com o sucesso que a companhia estava tendo em relação à venda de terras, o desenvolvimento da infraestrutura do patrimônio ali situado ocorreu amplamente ao longo dos anos até que em 1934, o interventor do estado, Manoel Ribas, elevou o status do patrimônio de Três Bocas para o município de Londrina, em homenagem à empresa inglesa que promoveu o avanço na região (SILVA, 2015).

Com ascendência italiana a família Belinati tem sua origem no município de Londrina catorze anos após a instalação do decreto ocorrido em 10 de dezembro 1934. Devido ao grande desenvolvimento da cidade e a necessidade de melhorar as ferrovias existentes a fim de escoar o grande produto que fomentava a economia londrinense: o café, o sobrenome Belinati aparece como o registro de José Mariosi Belinati, um ferroviário vindo transferido da Rede Ferroviária Federal para trabalhar no município (SILVA, 2015). Dá-se a partir daí o início de uma das famílias mais emblemáticas do cenário político paranaense e também brasileira.

De fato, o ingresso da família à política londrinense ocorre em 1968, com a eleição de Antônio Belinati como vereador. Filho de José Belinati, Antônio tem sua trajetória ao cargo do legislativo municipal percorrido por uma vasta popularidade adquirida por ter trabalhado como locutor de rádio e apresentador na cidade.

Em 1961, aos dezoito anos, Antônio Belinati começa a trabalhar como ajudante de Otássio Pereira, então vereador e radialista na Rádio Londrina (SILVA, 2015). Antônio tem breves aparições como radialista ao narrar propagandas publicitárias nas chamadas dos intervalos, porém a partir da convivência no meio

\footnotetext{
2 Dados disponíveis em: <http://www.londrina.pr.gov.br/index.php?option=com_content\&view= article\&id=3\&Itemid=5> Acesso em: 26 Nov. 2016
} 
artístico local, torna-se repórter policial no programa "A Voz do Paraná" e apresentador do "Telenotícias Transparaná", primeiro telejornal a ser transmitido pela extinta TV Coroados. Sua indicação se deu por conta da amizade que tinha com o delegado-chefe da subdivisão policial, Eudes Brandão, que por coincidência era chefe de jornalismo da emissora (ROCHA, 2004).

Com a substituição de Eudes Brandão por Mauro Ticianelli como chefe de jornalismo da emissora no final de 1966, Antônio Belinati também deixa o cargo e volta para a Rádio Londrina como locutor de um programa de 30 minutos de duração que entrou ao ar em 1967. Mesmo com o tempo curto, Belinati ganha muita popularidade pela audiência e filia-se ao partido de seu antigo chefe Otássio Pereira, o MDB, e concorre ao pleito do mesmo ano à Câmara Municipal, tornando-se, aos 25 anos, o vereador mais votado da cidade (SILVA, 2015).

Na metade de seu mandato como vereador, em 1970, Antônio elege-se Deputado Estadual e, projetado pela sua popularidade, concorre à Prefeitura de Londrina em 1972, porém é derrotado pelo candidato José Richa. Embora um Belinati houvesse sido derrotado pela primeira vez nas urnas, em dissonância à frustração de Antônio, emergia no mesmo ano mais um membro da família para o cenário político local: Valdimir Belinati, irmão de Antônio, que foi eleito vereador mais votado da cidade - seguindo os passos do irmão, sob a mesma legenda partidária, o Movimento Democrático Brasileiro (MDB).

Valdimir Belinati era estudante de Medicina quando assumiu seu primeiro mandato como vereador, usando-se do apoio e popularidade do irmão para angariar um cargo político no Legislativo da cidade aos 22 anos de idade.

Pode-se dizer que a partir de 1972, com ambos irmãos ocupando seus respectivos cargos eletivos pela cidade de Londrina, começa-se a dinastia Belinati que, ao longo dos anos, assume diversas formas de poder rodeado por inúmeros escândalos políticos como corrupção e nepotismo, não só na região londrinense, mas também no aparato do estado do Paraná, evidenciando o comportamento da classe dominante em alçar sua permanência no poder e utilizando-se dos meios públicos para obtenção de seus interesses privados.

\section{Conquista de Capital Político}

Como mencionado, pode-se dizer que o ano de 1972 deflagrou-se o início da trajetória política do sobrenome Belinati nos cargos eletivos londrinenses. Considerando o cenário político, o qual era integrado 
apenas pelos partidos da Aliança Renovadora Nacional (ARENA), partido situacionista no governo estadual e federal, e o Movimento Democrático Brasileiro (MDB), onde os dois irmãos encontravam-se filiados, a própria derrota nas urnas para à Prefeitura de Londrina de Antônio Belinati por José Richa demonstrava uma certa emancipação política da cidade em relação ao governo do Estado.

O fato de ambos irmãos estarem filiados ao MDB propiciou um acúmulo de capital político dentro do partido que acompanhariam os irmãos ao longo de suas trajetórias políticas e, consequentemente, de seus apadrinhados.

Dois anos após sua derrota para a Prefeitura, Antônio Belinati elege-se o segundo Deputado Federal mais votado do Paraná com aproximadamente 151 mil votos ${ }^{3}$. Tendo em vista a obtenção de tantos votos por parte do eleitorado londrinense, pode-se perceber o quão forte o poder político dos irmãos se tornava. Algo que também proporcionou essa elevação foi a presença de Antônio Belinati na Comissão de Segurança Nacional da Câmara dos Deputados em Brasília e também em seus programas de rádio que alastravam e demarcavam sua força política na região norte do estado (FGV-CPDOC).

Nesse mesmo período, por influência do irmão, Roberval Casemiro Belinati, estudante de Direito, inicia sua atividade como repórter no jornal Folha de Londrina, seguindo, mesmo que nos bastidores, os mesmos passos que Antônio dera antes de obter tamanha popularidade e prestígio.

O principal marco e demonstração do domínio Belinati na cidade de Londrina até então foi a eleição de Antônio à Prefeitura em 1976. Após derrotar Wilson Moreira por uma diferença de 10 mil votos, com 36.198 dos votos válidos - o que corresponderia a 30\% dos eleitores ${ }^{4}$ - Antônio interrompe seu mandato na Câmara em março do ano seguinte para tomar posse do governo local, tendo como vice José Antônio Del Ciel, um advogado e pecuarista membro da elite local. Porém, para sua eleição, sua campanha foi rodeada de críticas à própria elite que comandava a cidade, com alegações de que ela não representaria e atenderia as reais necessidades da população londrinense, o que causava certa preocupação do MDB em relação à sua candidatura. Nesse momento, há então uma cisão no partido em que certos membros apoiariam Belinati, e outros Wilson Moreira, como foi o caso de José Richa (SILVA, 2015).

Mesmo com essas adversidades Antônio Belinati vence o pleito, levando consigo o clamor popular obtido através de sua popularidade e aproximação do povo oriundo de seus programas de rádio. Concomitantemente à eleição de Antônio como prefeito, Waldmir reelege-se, novamente, como o vereador mais votado da cidade, e Roberval torna-se assessor na Câmara Federal.

\footnotetext{
${ }^{3}$ Fonte: Tribunal Regional Eleitoral - PR.

${ }^{4}$ Fonte: Tribunal Regional Eleitoral - PR.
} 
Uma vez alcançando o Executivo de Londrina, Antônio adota em seu governo uma postura populista, a qual é amplamente marcada pela criação de habitações populares na cidade, de autarquias para prestação de serviços e de obras públicas, e pela não quitação de empréstimos realizados em bancos para tais realizações. A fim de manter e reforçar seu poder, como prefeito criou entidades de associações de moradores dessas habitações com vínculos políticos entre seus líderes, o que garantiria um capital político para futuros cargos pretendidos.

A partir de vínculos com associações, Belinati aproveita para trazer sua esposa, Emília, ao cenário político londrinense, traçando assim mais uma linha com seu sobrenome na classe dominante local. Com sua posse como presidente da Associação de Proteção à Maternidade e à Infância (APMI) no ano de 1977, Emília Salles Belinati tem aí as portas abertas para sua trajetória política que viria a ser de extremo sucesso chegando ao Executivo do Estado com o cargo de vice-governadora do Paraná por duas vezes, ratificando o peso político que seu sobrenome possuía em cargos eletivos no estado (SILVA, 2015).

Após a extinção do bipartidarismo em 1979, sendo as eleições de 1980 adiadas por dois anos, Antônio Belinati filia-se ao PDS, Partido Democrático Social, e afasta-se do cargo de prefeito para tentar eleger-se como deputado estadual, porém só consegue assumir o posto devido à suplência ocorrida entre 1983 a 1987. Juntamente a isso, Roberval Belinati elege-se como o segundo vereador mais votado de Londrina para o ano, conseguindo manter-se no cargo por dois mandatos consecutivos ${ }^{5}$.

Enquanto isso, eleito em 1978 como o terceiro mais votado deputado federal pelo MDB, Waldmir presidiu o 1은 Simpósio Regional de Ecologia e Proteção ao Meio Ambiente, integrou a Comissão de Relações Exteriores e foi suplente da Comissão de Saúde da Câmara Federal. Aumentando sua visibilidade política e o capital do sobrenome da família (FGV-CPDOC).

Em 1986, sob a legenda do Partido Democrático Trabalhista (PDT), Antônio elege-se Deputado Estadual e, em 1989 consegue novamente assumir a prefeitura de Londrina, de modo a constatar a alternância entre os Poderes que praticava a cada fim de seu mandato, demonstrando o quão focado estava sua manutenção na classe dominante.

Após tomar posse como prefeito, Antônio nomeia seu irmão Waldmir como Secretário de Saúde da cidade para o primeiro biênio de seu mandato, e como Secretário-Geral no segundo, provocando o primeiro escândalo envolvendo nepotismo na região. Nesse mesmo ano, desponta como vereador mais um

\footnotetext{
5 Fonte: FGV-CPDOC - <http://www.fgv.br/cpdoc/acervo/dicionarios/verbete-biografico/Waldmir-belinati> Acesso
} em: 26 Nov. 2016 
de seus irmãos: José Belinati Filho, eleito com 4290 votos $^{6}$. Seu irmão Roberval torna-se Juíz Substituto do Tribunal de Justiça do Distrito Federal, enquanto que, em 1990, Emília Belinati elege-se à Câmara Estadual, sendo a única mulher a exercer o mandato durante os anos de 1991 a 1995.

Ao fim de seu mandato como prefeito (1993), Antônio deixa uma dívida de aproximadamente US\$ 22,9 milhões para seu sucessor e suspeitas de compra de votos de vereadores por meio de isenção de impostos, num total de 4.035 carnês de IPTU perdoados ${ }^{7}$.

Em 1994, mais uma vez, Antônio é eleito deputado estadual enquanto sua esposa Emília elege-se vice-governadora do Estado do Paraná na chapa de Jaime Lerner, e seu irmão Waldmir assume a superintendência do Instituto de Previdência do Estado (IPE). Um ano após tomar posse como deputado, Antônio interrompe seu mandato para concorrer, pela quarta vez, à Prefeitura de Londrina, conquistando o pleito e assumindo o cargo de prefeito em 1997 e, nesse mesmo ano, filia-se ao Partido da Frente Liberal (PFL) e empossa seu irmão Waldmir como diretor da Sercomtel S.A. Telecomunicações (SILVA, 2015).

Consoante à eleição do pai, no ano de 1998, Antônio Carlos Salles Belinati tem sua legislatura na Assembleia Legislativa do Paraná conquistada sob a legenda do Partido Socialista Brasileiro (PSB).

No mesmo ano, a Copel compra $45 \%$ das ações da Sercomtel por $\mathrm{R} \$ 186$ milhões, sendo parte desse valor depositado no Cogefi, um fundo criado por Belinati para desenvolver diversos projetos na cidade. Porém, nenhuma obra é realizada nesse período. Surgem então denúncias de que parte do dinheiro foi desviada para as campanhas eleitorais em 1998 do então governador Jaime Lerner e de Antônio ${ }^{8}$.

Em 15 de maio de 2000 o afastamento de Belinati é decretado, sendo ele responsabilizado por desvio de dinheiro público, nepotismo, enriquecimento ilícito, fraude de licitações, entre outras irregularidades, e em 23 de junho de 2000, após uma sessão histórica na Câmara de vereadores, é cassado por 14 votos a 6, com apontamentos de gastos irregulares de R\$ 113 milhões 9 .

Nota-se por esses fatores, que a apropriação do capital político adquirido por Antônio Belinati desde sua eleição como vereador da cidade de Londrina, até sua conquista à Câmara Federal e à Prefeitura,

\footnotetext{
${ }^{6}$ Fonte: Tribunal Regional Eleitoral - PR.

7 Fonte: <http://janela-londrinense.blogspot.com.br/2010/08/historico-de-um-politico.html> Acesso em: 26 Nov. 2016

8 Fonte: <http://janela-londrinense.blogspot.com.br/2010/08/historico-de-um-politico.html> Acesso em: 26 Nov. 2016

9 Fonte: FGV-CPDOC. <http://www.fgv.br/cpdoc/acervo/dicionarios/verbete-biografico/antonio-casemiro-belinati> Acesso em: 26 Nov. 2016
} 
fez com que membros de sua família fossem alçados ao alto escalão da política simplesmente pela relação parental existente, que foi passado para as futuras gerações ao longo dos anos.

Rodeado por escândalos políticos como nepotismo, fraudes contratuais, enriquecimento ilícito, entre outros crimes, o sobrenome Belinati destaca-se no cenário político local e estadual devido à esses e outros elementos que envolvem a família. Embora haja a presença de tantos escândalos, o peso da força desse sobrenome na política parecem não ter sido dizimados mesmo após a cassação de um de seus membros, sendo a prova disso a própria reeleição de Antônio Belinati à Prefeitura de Londrina em 2008 impugnada pelo TSE acarretando novas eleições para prefeito da cidade - e, atualmente, a eleição de Marcelo Belinati à Prefeitura de Londrina no ano de 2016 (SILVA, 2016).

Pode-se perceber que há uma alternância entre os setores ocupados pelos membros da família, alternando-se entre o Legislativo Municipal, Estadual e Federal entre os quatro irmãos Belinati, tal como no Poder Executivo da cidade de Londrina e do estado do Paraná, por parte de Antônio Belinati e Emília Salles, entre outras formas de manter-se na classe dominante local através de nomeações para cargos de diretorias e gestão. Essa mescla de atuações em vários âmbitos do Poder foi capaz de fazer com que o sobrenome fosse perpetualizado na política local de modo com que, mesmo com indícios criminosos que criaram suspeita sobre seus integrantes, a família Belinati ainda assuma um papel de destaque em todas as eleições que disputam, conseguindo uma considerável expressividade de votação em relação a seus oponentes. Fato que demonstra a solidez do capital político iniciado por seus pioneiros na política londrinense e mantido e renovado ao longo dos anos por seus descendentes devido ao habitus ${ }^{10}$ retido sob o domínio Belinati.

\section{Manutenção do Poder}

Atualmente encontram-se membros da família Belinati em diversos cargos de diretoria, chefia, cargos concursados e outros comissionados em diversas instituições governamentais ou não. Nomes como Antônio Carlos Salles Filho, deputado estadual de 1999 a 2002 e diretor da Sanepar entre 2011 e 2013;

10 O conceito de habitus é empregado por Pierre Bourdieu em sua obra O Poder Simbólico (1989), sendo definido como as representações de uma determinada estrutura social presente em um indivíduo que o leva a pensar e agir de acordo com um sistema de práticas adquiridas pelas experiências do cotidiano e voltadas para ele. 
Marcos Roberto Guazzi Belinati, vereador de Londrina desde 2013; e Marcelo Belinati, atual prefeito eleito de Londrina são exemplos de continuidade do legado existente com a assinatura Belinati ${ }^{11}$.

Dentre esses e outros membros da família, pode-se destacar Marcelo Belinati pelo fato de ter sido eleito para o Executivo londrinense em 2016. Nascido em 1971 e formado em Direito pela Universidade Estadual de Londrina, Marcelo tem sua primeira eleição para o cargo de vereador em 2004 pelo Partido Social Liberal (PSL), em sua segunda tentativa, sendo o candidato mais votado. Em 2008, retorna à Câmara Municipal recebendo novamente o maior número de votos do pleito. (SILVA, 2016).

Considerando a conquista do primeiro lugar nas duas votações para vereador, pode-se perceber o quão popular e forte o sobrenome da família era, dando a seus membros lugar de destaque na política local.

Após cumprir seu mandato como vereador pela segunda vez, Marcelo lança-se candidato à Prefeitura de Londrina em 2012 pelo Partido Progressista (PP), porém é derrotado pelo pecuarista Alexandre Kireeff por um placar apertado de $48,14 \%$ a $47,12 \%^{12}$ no segundo turno da disputa, sendo que a região em que havia recebido mais votos da população era justamente a região em que seu tio, Antônio Belinati, havia construído habitações populares em sua primeira gestão como prefeito. (SILVA, 2016).

Esse fato evidencia que a forma populista de governo, proporcionando a criação de um sítio eleitoreiro, uma vez que este seja conquistado, tende-se a resignar e acompanhar os futuros integrantes de um mesmo grupo político ao longo dos anos, independentemente das manchas causadas por denúncias, escândalos e desgastes sobre a imagem desse grupo.

Dando continuidade à sua trajetória, Marcelo elege-se Deputado Federal em 2014, trazendo mais uma vez um Belinati para o legislativo nacional. Entretanto, no ano de 2016 afasta-se do cargo para concorrer às eleições de 2016 à Prefeitura de Londrina, obtendo êxito em sua segunda tentativa (SILVA, 2016).

Com a conquista de mais um Belinati ao cargo mais importante da cidade de Londrina é constatado que o poder político, angariado inicialmente por Antônio Belinati e difundido e renovado pelos irmãos, esposa, filhos e sobrinhos, é extremamente concentrado ante ao grupo Belinati que tende a migrar de posições e cargos políticos, garantindo o capital obtido a cada eleição para as futuras gerações, tal como seu curral e.

${ }_{11}$ Fonte: <http://www.doclondrina.blogspot.com.br/2015/12/a-historia-dos-clas-de-londrina.html> Acesso em: 26 Nov. 2016

${ }^{12}$ Fonte: Tribunal Regional Eleitoral - PR. 
Não pode-se deixar de fora dessa análise sobre a família o fato de sempre estarem alinhados a setores da elite local, que também constitui parte da classe dominante da região londrinense, e que fornece um importante apoio e garantem os interesses particulares dos membros de seus grupo.

\section{Considerações Finais}

Tendo em vista a solidificação do nome Belinati nos cenários políticos municipal, estadual e federal, vê-se que a trajetória política dos membros da família é realizada não só por meio de sufrágios direto, mas também por nomeações, como no caso do escândalo de nepotismo entre os irmãos Antônio e Waldmir Belinati, e através de aprovações em concursos, como Roberval, atual desembargador do Superior Tribunal de Justiça do Distrito Federal e dos Territórios.

À medida em que seu pioneiro político, Antônio Belinati tem êxito em suas disputas eleitorais para diversos cargos no Legislativo, tem-se aí oportunidades constituídas para abranger membros de sua família ao cenário político, de modo a demarcar o território sob o domínio Belinati que estende-se e amplia-se ao passar dos anos.

Isto posto, percebe-se que a história e o progresso da cidade de Londrina, por tratar-se de uma cidade ainda nova, é intrinsecamente ligada à prosperidade da família, que através da proximidade com o povo angariada por seu pioneiro político, tem sua posição dominante amparada pela própria população e seu capital político aumentado por meio de relações entre a elite local mantidas ao longo dos anos. Atualmente, gozam desta situação Marcelo e Marcos Roberto Belinati, ambos sobrinhos de Antônio Belinati e com cargos eletivos a serem cumpridos pela cidade. Indicando o enraizamento de seus sobrenomes na política.

\section{Referências}

Doc.Londrina. A história dos clãs de Londrina. Disponível em: <http: //www.doclondrina.blogspot.com.br/2015/12/a-historia-dos-clas-de-londrina.html>. Acesso em 26 Nov. 2016

FGV-CPDOC. Antônio Belinati. Disponível em: <http://www.cpdoc/acervo/dicionarios/verbetebiografico/antonio-casemiro-belinati>. Acesso em 26 Nov. 2016 
FGV-CPDOC. Waldmir Belinati. Disponível em: <http://www.fgv.br/cpdoc/acervo/dicionarios/verbetebiografico/Waldmir-belinati>. Acesso 26 Nov. 2016

MACIEL, Marcel Nagao. A trajetória política de Antônio Casemiro Belinati. Disponível em: <http://janela-londrinense.blogspot.com.br/2010/08/historico-de-um-policio.html>. Acesso em 26 Nov. 2016

ROCHA, Ederval Camargo. História da TV Coroados - Londrina (PR). Florianópolis, 2004.

SILVA, Carla Andréia Alves da. Famílias e Eleições Municipais em Londrina. Curitiba, 2016.

Relações de Poder Político e Parentesco no Município de Londrina - Paraná. - 274f. Dissertação (Sociologia) Universidade Federal do Paraná - Curitiba, 2015.

TJTFT. 96 - $\quad$ Desembargador Roberval Casemiro Belinati. Disponível em: $<$ http://www.tjdft.jus.br/institucional/centro-de-memoria-digital/biografias/96 RobervalCBelinati.pdf>. Acesso em: 26 Nov. 2016

\section{Bibliografia Consultada}

OLIVEIRA, Ricardo Costa. O silêncio dos vencedores: genealogia, classe dominante e estado no Paraná. Curitiba: Moinho do Verbo, 2001.

OLIVEIRA, Ricardo Costa. Na teia do nepotismo: sociologia política das relações de parentesco e poder político no Paraná e no Brasil. Curitiba: Moinho do Verbo, 2001.

PREFEITURA de Londrina. História da Cidade. Disponível em: $<h t t p: / / w w w . l o n d r i n a . p r . g o v . b r / i n d e x . p h p ? o p t i o n=c o m \_c o n t e n t \& v i e w=a r t i c l e \& i d=3 \& \mid t e m i d=5>$. Acesso em: 26 Nov. 2016

TRE-PR. Resultados de eleições municipais TRE-PR. Disponível em: <http://www.trepr.jus.br/eleicoes/resultados/resultados-de-eleicoes-municipais-tre-pr>. Acesso em: 26 Nov. 2016 